\title{
Exosomal TRIM3 is a novel marker and therapy target for gastric cancer
}

\author{
Hailong Fu ${ }^{1,2+}$, Huan Yang ${ }^{1,3+}{ }^{+}$Xu Zhang $^{1 \dagger}$, Bo Wang ${ }^{4}$, Jiahui Mao ${ }^{1}$, Xia Li ${ }^{1}$, Mei Wang ${ }^{1}$, Bin Zhang ${ }^{1}$, Zixuan Sun ${ }^{1}$, \\ Hui Qian ${ }^{1 *}$ and Wenrong $X u^{1 *}$
}

\begin{abstract}
Background: Exosomes are critically involved in cancer development and progression. The exosomal contents have been suggested as ideal cancer biomarkers. In this study, we investigated the expression of exosomal proteins in the serum of gastric cancer patients and their roles in gastric cancer.

Methods: The proteomic profile of exosomes from the serum of gastric cancer patients was detected by using LC-MS/MS. The expression of TRIM3 in exosomes from the serum of gastric cancer patients and healthy controls was assessed by ELISA and western blot. Immunohistochemistry was used to detect TRIM3 expression in gastric cancer tissues and their matching adjacent tissues. The growth and migration abilities of gastric cancer cells with TRIM3 overexpression or knockdown in vitro were evaluated by colony formation assay and transwell migration assay. The effects of TRIM3 overexpression or knockdown on gastric cancer growth and metastasis in vivo were investigated by using subcutaneous xenograft tumor and peritoneal metastasis mouse model. The effects of TRIM3-overexpressing exosomes on gastric cancer growth and metastasis in vitro and in vivo were also evaluated.

Results: We found that the expression levels of TRIM3 mRNA and protein were decreased in gastric cancer tissues compared to the matched control tissues. In addition, the levels of TRIM3 protein in the serum exosomes of gastric cancer patients were lower than that in healthy controls. We demonstrated that TRIM3 overexpression reduced while TRIM3 knockdown promoted the growth and metastasis of gastric cancer in vitro and in vivo through the regulation of stem cell factors and EMT regulators. Moreover, exosomes-mediated delivery of TRIM3 protein could suppress gastric cancer growth and metastasis in vitro and in vivo.
\end{abstract}

Conclusions: Taken together, our findings suggest that exosomal TRIM3 may serve as a biomarker for gastric cancer diagnosis and the delivery of TRIM3 by exosomes may provide a new avenue for gastric cancer therapy.

Keywords: Gastric cancer, Exosomes, TRIM3, Progression, Diagnosis, Therapy

\section{Background}

Gastric cancer $(\mathrm{GC})$ is the fourth most common cancer in the world and the second leading cause of cancer-related deaths. It is estimated that there are approximately 750,000 new cases diagnosed annually around the world, and 5-year overall survival rates are less than $25 \%$ [1]. In spite of the progress in chemotherapy, radiotherapy and surgical techniques for GC in recent years, the survival rate of GC patients remains unsatisfactory [2]. One of the main

\footnotetext{
*Correspondence: Istmmmlst@163.com; icls@ujs.edu.cn

†Hailong Fu, Huan Yang and Xu Zhang contributed equally to this work.

${ }^{1}$ Jiangsu Key Laboratory of Medical Science and Laboratory Medicine, School of Medicine, Jiangsu University, 301 Xuefu Road, Zhenjiang 212013, Jiangsu, China

Full list of author information is available at the end of the article
}

reasons for the low overall survival is the lack of appropriate molecular biomarkers, which results in most of GC patients being diagnosed at advanced stage, missing the best opportunity for curative surgery.

Exosomes are small vesicles with several unique properties such as classic dish or cup morphology, 50$100 \mathrm{~nm}$ in diameter, double lipid layer, and a density of $1.12-1.19 \mathrm{~g} / \mathrm{mL}[3,4]$. Exosomes are generated from the internal vesicles of multivesicular bodies (MVBs), which release their contents into biological fluids $[5,6]$. Exosomes in the body fluids such as blood and urine could serve as diagnostic markers for various diseases including cancer because they may reflect the pathological state of their derived cells [7-9]. Exosomes contain 
proteins, nucleic acids, and lipids, which usually vary with the cellular and tissue origins of the exosomes and are adapted to their functions $[10,11]$. The identification and isolation of cancer cells derived exosomes in body fluids could enable the specific detection of DNA, RNA, and proteins, which will aid in the diagnosis and treatment of cancer.

Tripartite motif (TRIM) proteins, one of the subfamilies of the RING-type E3 ubiquitin ligases, are regarded as critical regulators of neoplastic processes [12, 13]. These proteins play important roles in a variety of biological processes, such as cell proliferation, cell differentiation, DNA repair, transcriptional regulation, and apoptosis [12, 13]. Tripartite motif-containing 3 (TRIM3) is a member of the TRIM protein family, which maps to chromosome $11 \mathrm{p} 15.5[14,15]$. It has been reported that the loss of TRIM3 gene promotes the development and progression of glioblastomas, while overexpression reduces the tumorigenicity of GBM. The tumor suppressive function of TRIM3 in GBM may be linked to its regulation of p21 [16, 17]. TRIM3 has also been reported to be lowly expressed in glioma cells [18]. However, the roles of TRIM3 in gastric cancer have not been well characterized.

In the present study, we isolated exosomes from the serum of gastric cancer patients and identified the proteomic profile of serum exosomes. We found that TRIM3 protein level was decreased in the serum exosomes of gastric cancer patients compared to that in healthy controls. TRIM3 exerted a tumor suppressive role in gastric cancer. TRIM3 overexpression inhibited while TRIM3 knockdown promotedthe growth and metastasis of gastric cancer through the regulation of stem cell factors and EMT regulators. Moreover, we demonstrated that exosomes-mediated delivery of overexpressed TRIM3 could suppress gastric cancer growth and metastasis in vitro and in vivo.

\section{Methods}

\section{Cell lines and cell culture}

Human gastric cancer cell lines SGC-7901 and MGC-803, normal gastric epithelial cell line GES-1, and HEK-293 cell line were purchased from the Institute of Biochemistry and Cell Biology at the Chinese Academy of Sciences (Shanghai, China). The cells were propagated in RPMI-1640 medium (Gibco, Grand Island, USA) supplemented with $10 \%$ fetal bovine serum (FBS; Gibco). The cells were cultured at $37^{\circ} \mathrm{C}$ in humidified air with $5 \% \mathrm{CO}_{2}$.

\section{Human gastric cancer samples}

Peripheral blood samples were collected after obtaining informed consent from 80 gastric cancer patients (63 male and 17 female), and 80 healthy volunteers (50 male and 30 female) used as age and sex matched control groups, which were collected from the Affiliated Peoples' Hospital of Jiangsu University, China. Blood samples were centrifuged and serum was isolated and kept at $80{ }^{\circ} \mathrm{C}$ until analysis. The serum samples of 20 gastric cancer patients (14 male and 6 female) and age matched 20 healthy volunteers (13 male and 7 female) were collected from the Affiliated Peoples' Hospital of Jiangsu University. Paraffin sections of 20 (13 male and 7 female) gastric cancer and adjacent noncancerous tissues were collected from the Affiliated Peoples' Hospital of Jiangsu University, China. The primary gastric cancer tissues and their matched, adjacent noncancerous tissues (located more than $5 \mathrm{~cm}$ away from the primary site) were collected from 60 gastric cancer patients (46 male and 14 female) undergoing surgery at the Affiliated Peoples' Hospital of Jiangsu University, China. Informed consent was given in all patients examined. All samples were confirmed by pathological examination. Histological grade was defined according to the World Health Organization classification. Documented informed consent was obtained from all subjects and the Ethics Committee of Jiangsu University approved all aspects of the study (2012258).

\section{Exosome isolation}

Exosomes were obtained from the serum and the culture supernatants by using ExoQuick precipitation solution (System Biosciences, Mountain View, CA, USA) according to manufacturer's instructions. Briefly, $250 \mu \mathrm{L}$ of serum were mixed with $63 \mu \mathrm{L}$ of ExoQuick solution and incubated overnight at $4{ }^{\circ} \mathrm{C}$. After centrifugation at $1500 \mathrm{~g}$ for $30 \mathrm{~min}$, the pellets were suspended in $50 \mu \mathrm{L}$ PBS. The culture supernatants from cells that had grown to sub-confluence $(70-80 \%)$ in serum-free medium were harvested. The appropriate volume of ExoQuick-TC Exosome Precipitation Solution was added into the cell supernatant (1:5 ratio) and incubated at $4{ }^{\circ} \mathrm{C}$ overnight. After centrifugation at $1500 \mathrm{~g}$ for $30 \mathrm{~min}$, the pellets were resuspended in PBS and filtrated through a $0.22 \mu \mathrm{m}$ filter (EMD Millipore, Billerica, MA, USA). The isolated exosomes were stored at $70{ }^{\circ} \mathrm{C}$ until use.

\section{Transmission electron microscopy}

Twenty microliters of the prepared exosomes were pipetted onto formvar carbon-coated copper grids and allowed to adsorb for $10 \mathrm{~min}$ before excess fluid was drained. The adsorbed exosomes were then negatively stained with $2 \%(w / v)$ phospphotungstic acid $(\mathrm{pH} 6.8)$ for $5 \mathrm{~min}$ and was air-dried under an electric incandescent lamp, and analyzed with a transmission electron microscope (FEI Tecnai 12, Philips), bar $=50 \mathrm{~nm}$. 


\section{Size and concentration analyses of exosomes}

The isolated exosomes were diluted in PBS and were analyzed using a NanoSight LM 10-HSBFT 14 Instrument (NanoSight, Malvern, UK) according to the manufacturer's protocol. The size and concentration of exosomes were then analyzed by using the Nanoparticle Tracking Analysis 2.0 (NTA 2.0) software.

\section{LC-MS/MS analysis}

Exosomes were obtained from the serum of gastric cancer patients and healthy controls $(n=3)$ with ExoQuick precipitation solution (System Biosciences, Mountain View, CA, USA) according to manufacturer's instructions. The serum exosomes were re-suspended in $50 \mu \mathrm{l}$ of PBS, $2 \mu \mathrm{l}$ triton X-100, and $5 \mu$ phenylmethylsulfonyl fluoride with vortexing to dissolve the vesicles. The insoluble fraction was pelleted by centrifugation $20,000 \mathrm{~g}$. The insoluble fraction was acetone precipitated at $-20{ }^{\circ} \mathrm{C}$ and digested in-gel with $1 \mu \mathrm{g} / \mathrm{ul}$ trypsin (sequencing grade, Promega) for $18 \mathrm{~h}$ at $37^{\circ} \mathrm{C}$. Resulting peptides were analyzed by LC-MS/MS on an Q-ExactiveOrbitrap mass spectrometer (Thermo Scientific, Waltham MA, USA). Fold change means the ratio of direct reporter group strength, this experiment selected 1.13 times as the difference threshold, and $P$ value $<0.05$.

\section{ELISA for TRIM3 detection}

Exosomes were homogenized and lysed in RIPA buffer supplemented with proteinase inhibitors. TRIM3 concentration in exosomes was measured by using a commercial ELISA Kit according to the manufacturer's instruction (Sanco, Hong Kong, China). The absolute amount of TRIM3 protein was calculated based on standard curves using human recombinant TRIM3 as the standard material. The concentration of TRIM3 was expressed as pictograms per milliliter.

\section{TRIM3 plasmid transfection}

The TRIM3 expression vector and control vector were purchased from Genechem (Shanghai, China). The TRIM3 expression vector or control vector were transfected into MGC-803 and SGC-7901 cells by using Lipofectamine 2000 (Invitrogen, Carlsbad, CA, USA) according to the manufacturer's instructions. The expression of TRIM3 was confirmed by using real-time quantitative RT-PCR and western blot at $48 \mathrm{~h}$ after transfection.

\section{siRNA transfection}

Chemically synthesized TRIM3 siRNA and the scramble control siRNA were purchased from Genepharma (Shanghai, China). The sequences of siRNAs are shown in Additional file 1: Table S1. The siRNAs were transiently transfected into MGC-803 and SGC-7901 cells by using Lipofectamine 2000 reagent (Invitrogen, Carlsbad, CA, USA) according to the manufacturer's instructions. Cells were plated in 6-well plates at a density of $1 \times 10^{5}$ cells/well.

\section{Exosome treatment}

MGC-803 and SGC-7901 cells were treated with various doses of control and TRIM3-overexpressing exosome $(10 \mu \mathrm{g}, 25 \mu \mathrm{g}, 50 \mu \mathrm{g})$ and cultured for $48 \mathrm{~h}$, MGC-803 cells were treated with TRIM3-overexpressing exosome derived from MGC-803 cells and SGC-7901 cells were treated with TRIM3-overexpressing exosome derived from SGC-7901 cells.

\section{Colony formation assay}

Cells were harvested and seeded into $35 \mathrm{~mm}$ plates (1000 cells/well) and incubated for 10 days under standard conditions. At the end of the incubation period, the colonies were fixed with $4 \%$ paraformaldehyde and stained with crystal violet.

\section{Transwell migration assay}

Cells $\left(1 \times 10^{5} /\right.$ well $)$ were plated into the top chamber and $10 \%$ FBS containing medium was placed into the bottom chamber. After incubation at $37{ }^{\circ} \mathrm{C}$ in $5 \% \mathrm{CO}_{2}$ for $12 \mathrm{~h}$, the cells remaining at the upper surface of the membrane were removed with a cotton swab. The cells that migrated through the $8 \mu \mathrm{m}$ sized pores and adhered to the lower surface of the membrane were fixed with $4 \%$ paraformaldehyde, stained with crystal violet and photographed.

\section{RNA extraction, RT-PCR and real-time RT-PCR}

Total RNA was extracted from cells and tissues using TRIZOL Reagent (Invitrogen, Carlsbad, CA, USA) according to the manufacturer's instructions. Total RNA was extracted from serum exosomes using QIAGEN RNA extraction Kit and equal amount of RNA was used for RT-PCR and real-time RT-PCR analyses. $\beta$-actin was used as the internal control. The sequences of specific primers are listed in Additional file 2: Table S2.

\section{Western blot}

The cells and isolated exosomes were homogenized and lysed in RIPA buffer supplemented with proteinase inhibitors. Equal amount of proteins was loaded and separated on a $10 \%$ SDS-PAGE gel. Following electrophoresis, the proteins were transferred to a PVDF (polyvinylidene difluoride) membrane, blocked in 5\% $(w / v)$ non-fat milk and incubated with the primary antibodies. The sources of primary antibodies were: GAPDH and E-cadherin (Cell Signaling Technology, Beverly, MA, USA); N-cadherin (Abcam, USA); Sox2 (Millipore, USA); PCNA (Bioworld Technology, Louis Park, MN, 
USA); Oct4,Vimentin (Signalway Antibody, USA); GAPDH, Goat anti rabbit IgG (HRP), and Goat anti mouse IgG (HRP) (CWBIO, China).

\section{Animal model}

The animal studies were performed with approval of the University Committee on Use and Care of Animals of Jiangsu University. The male $\mathrm{BALB} / \mathrm{c} \mathrm{nu} / \mathrm{nu}$ mice aged 4-6 weeks were purchased from the Laboratory Animal Center of Shanghai (Academy of Science, Shanghai, China) and were randomly divided into six groups $(n=6)$.

\section{Tumor growth assay in vivo}

Two groups received subcutaneous injections of either vector or TRIM3-overexpressing MGC-803 cells $\left(2 \times 10^{6}\right.$ cells in $200 \mu \mathrm{l}$ PBS), and two groups received subcutaneous injections of either NC-siRNA or TRIM3-siRNA transfected MGC-803 cells $\left(2 \times 10^{6}\right.$ cells in $200 \mu \mathrm{l}$ PBS). MGC-803 pre-treated with TRIM3-overexpressing or control exosomes were subcutaneously injected into the two-flank of BALB/c nude mice $\left(2 \times 10^{6}\right.$ cells in $200 \mu \mathrm{l}$ PBS). Tumors were surgically removed 20 days after injection, photographed and weighted. Tumor volume was assessed by caliper measurement and calculated by the formula $(\mathrm{L} \times \mathrm{W} \times \mathrm{W} / 2)$, where $\mathrm{L}$ represents length, and $\mathrm{W}$ represents width.

\section{Tumor metastasis assay in vivo}

The mice were grouped as described above. MGC-803 cells were intraperitoneally injected into the mice $\left(2 \times 10^{6}\right.$ cells in $500 \mu \mathrm{l}$ PBS). Mice were inspected every 2 days and killed at 1 month after injection. The metastatic tumor nodes were removed and examined.

\section{Vector construction and luciferase activity assay}

The 3' untranslated regions (3'-UTR) of TRIM3 mRNA were obtained by PCR and ligated into the pmirGLO dual-luciferase miRNA target expression vector (Promega, Madison, WI, USA). The mutant constructs were generated using Quick Change II Site-Directed Mutagenesis Kit (Agilent Technologies, Santa Clara, CA, USA). MiRNA-20a mimics and NC-mimics, miRNA-20a inhibitors and NC-inhibitor were purchased from Genepharma (Shanghai, China), and the sequences are shown in Additional file 3: Table S3. For the overexpression studies, HEK-293 cells were co-transfected with $500 \mathrm{ng}$ reporter vector with miRNA-20a mimics or NC-mimics. For the knockdown studies, HEK-393 cells were co-transfected with $500 \mathrm{ng}$ reporter vector with miRNA-20a inhibitors or NC-inhibitor. Firefly luciferase activity was examined after transfection by using a dual-luciferase reporter assay system (Promega, USA) and normalized to that of Renilla luciferase.

\section{Immunohistochemistry}

The protein levels of TRIM3 in formalin-fixed paraffinembedded gastric cancer tissues and adjacent non tumor tissue were detected by immunohistochemistry. Briefly, the sections were incubated with primary antibody and secondary antibody, visualized with 3,3'-diaminobenzidine (DAB) and then counterstained with hematoxylin for examination by the microscope. Twenty gastric cancer tissues and the corresponding adjacent noncancerous normal tissues were chosen randomly. The sections were photographed under a microscope and at least six fields were examined.

\section{Statistical analyses}

All results were confirmed in at least three independent experiments, and data from one representative experiment were shown. Data are presented as the mean \pm SD. A two-tailed Student's t-test was used to test the differences in sample means for data with normally distributed means. Mann-Whitney U-test was used for non-parametric data. The statistical analysis was performed using SPSS Statistics software. Values of $P<0.05$ were considered significant.

\section{Results}

The characterization of exosomes from the serum of gastric cancer patients

The results of transmission electron microscope analysis showed that exosome derived from the serum of gastric cancer patients and healthy controls were dish- or cup-like vesicles with $50-100 \mathrm{~nm}$ in diameter and double lipid layer (Fig. 1a). The concentration of exosomes from the serum of gastric cancer patients was higher than that from healthy control $(P<0.01)$ (Fig. 1b). The diameter of exosomes from the serum of gastric cancer patients was similar to that from healthy controls (Fig. 1c). In addition, the concentration of exosome from the culture supernatant of gastric cancer cells MGC-803 and SGC-7901 were also higher than that from gastric epithelial cells GES-1 $(P<0.01)$ (Fig. 1e). However, the diameter of exosome from the culture supernatant of gastric cancer cells MGC-803 and SGC-7901 has no difference with that from gastric epithelial cells GES-1 (Fig. 1f).

\section{Proteomic analyses of exosomes from the serum of gastric cancer patients}

Three pairs of serum samples were collected from gastric cancer patients and healthy controls and the isolated exosomes from the serum samples were used for LC-MS/MS analyses. A total of 243 differentially expressed proteins were identified in the serum exosomes of gastric cancer patients, of which 33 proteins (7 upregulated and 26 downregulated) showed significant 


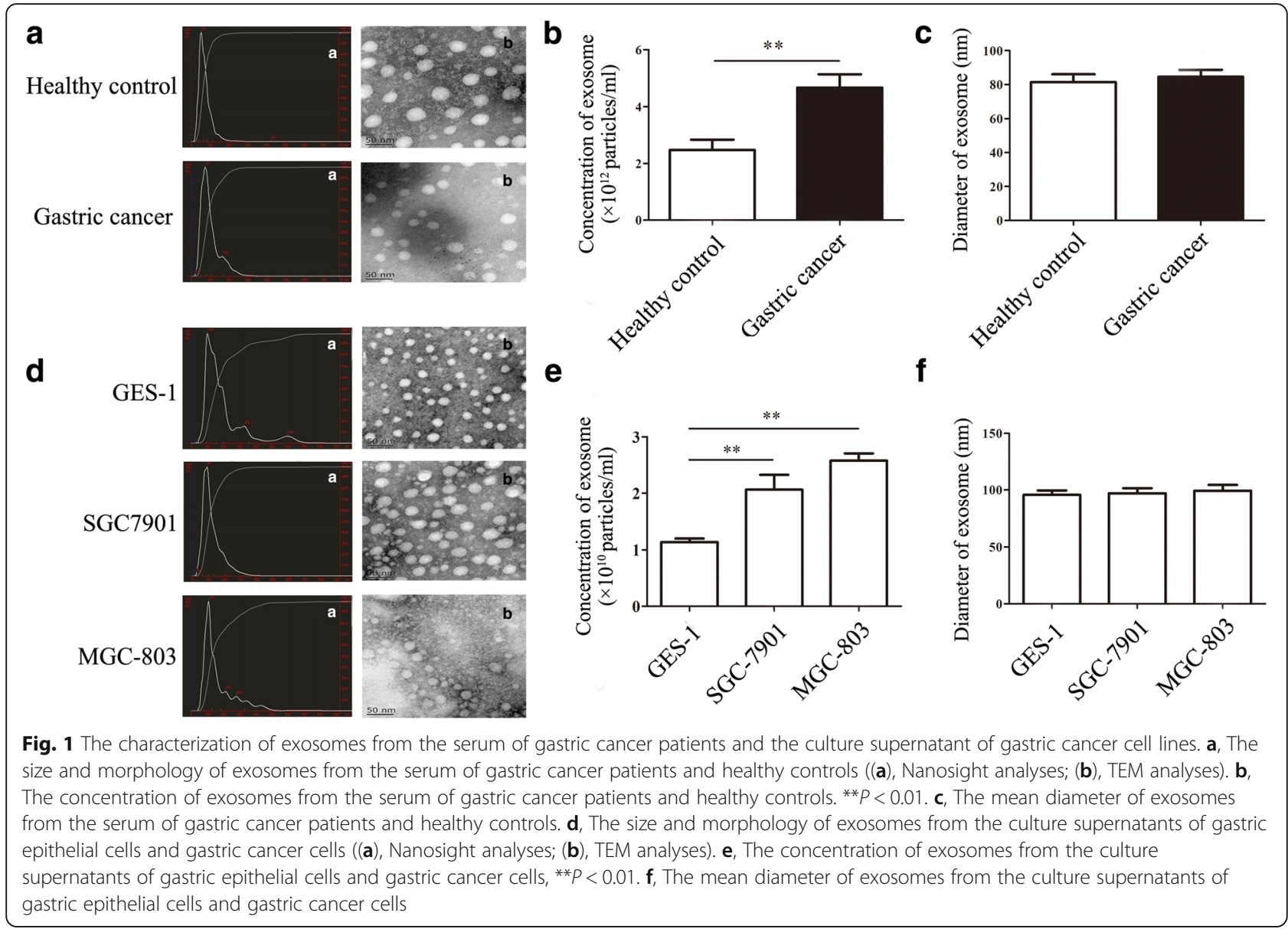

difference between gastric cancer patients and healthy controls $(P<0.05)$ (Fig. 2a) (Additional file 4: Figure S1).

\section{TRIM3 is downregulated in gastric cancer}

We next verified the expression of TRIM3 in gastric cancer tissues and serum exosomes. We performed ELISA to detect TRIM3 expression in exosomes that were extracted from 80 pairs of gastric cancer patients and healthy controls. The results showed that the expression of TRIM3 in exosomes from the serum of gastric cancer patients was much lower than that from the healthy controls, which was further confirmed by western blot assay (Fig. 2b). We next determined the expression of TRIM3 in gastric cancer tissues and adjacent control tissues by using real-time quantitative reverse transcription PCR (qRT-PCR). We found that the expression of TRIM3 was lower in gastric cancer tissues than the paired control tissues in most cases (Fig. 2e). We then conducted immunohistochemistry (IHC) to examine TRIM3 expression in 20 pairs of gastric cancer tissues and adjacent control tissues. We found that TRIM3 was detectable in 15\% (3/20) of the gastric cancer tissues and $75 \%(15 / 20)$ of adjacent control tissues (Fig. 2f). The positive rate of TRIM3 was much lower in tumor tissues than adjacent control tissues. We detected the expression of TRIM3 in gastric cancer cells and gastric epithelial cells. TRIM3 protein levels were much lower in MGC-803 and SGC-7901 cells than in GES-1 cells. The decreased expression of TRIM3 was also observed in exosome from the culture supernatant of MGC-803 and SGC-7901 cells compared to that from GES-1 cells (Fig. 2c, d).

\section{TRIM3 overexpression inhibits the proliferation and migration of gastric cancer cells in vitro}

We next determined the roles of TRIM3 in gastric cancer. TRIM3 was overexpressed in gastric cancer cells by transient transfection. The results of qRT-PCR and western blot confirmed the increase of TRIM3 expression after transfection (Additional file 5: Figure S2a, b). As shown in Fig. 3a and b, TRIM3 overexpression reduced colony formation ability in MGC-803 and SGC-7901cells. TRIM3 overexpression decreased the expression of OCT4 and SOX2, two factors that have been reported to play important roles in cell proliferation, in MGC-803 $(P<0.05, P<0.05)$ and SGC-7901 cells $(P<0.01, P<0.05)$ (Fig. $3 \mathrm{c}, \mathrm{d})$. The overexpression of TRIM3 inhibited cell migration in both MGC-803 

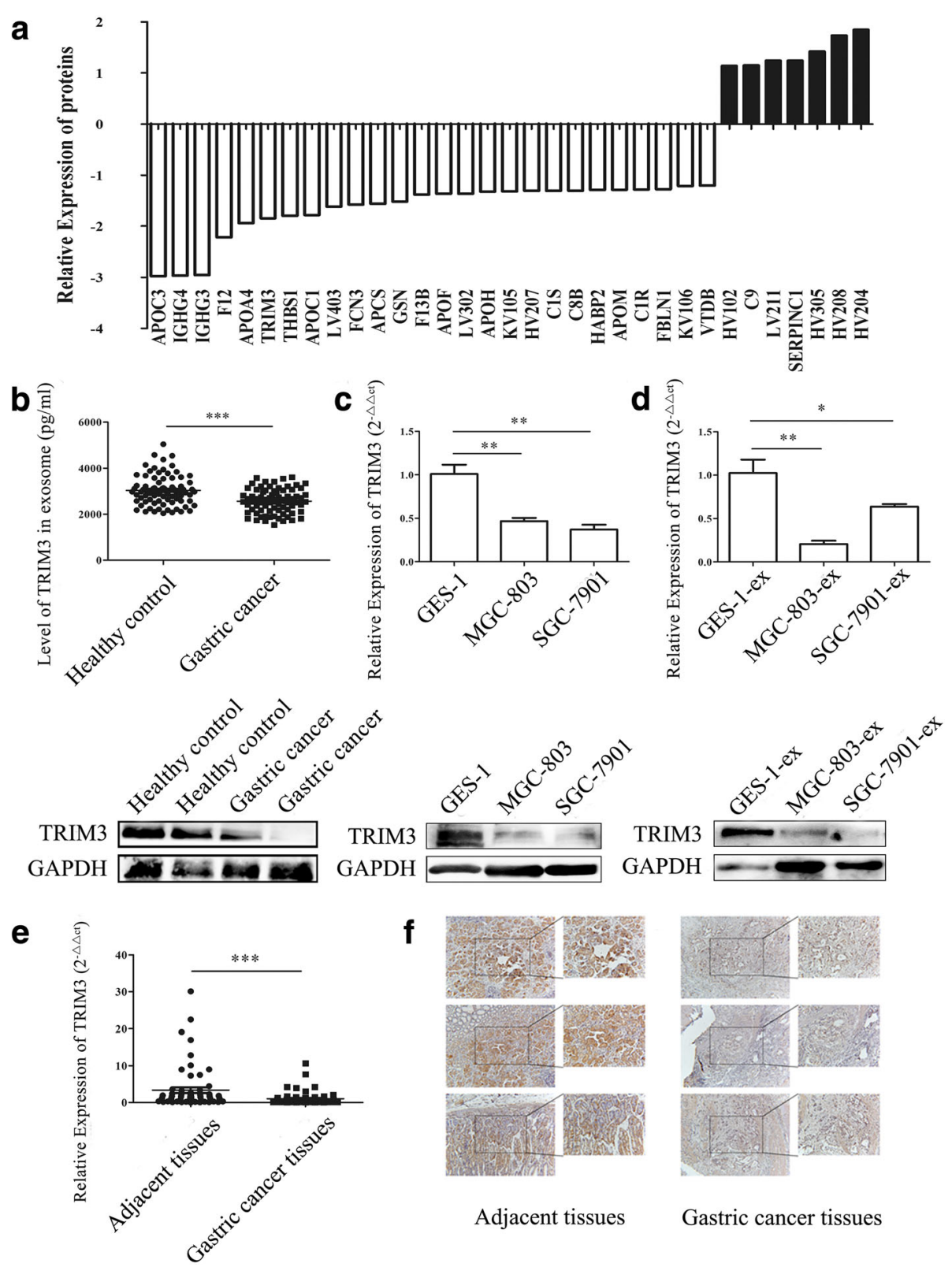

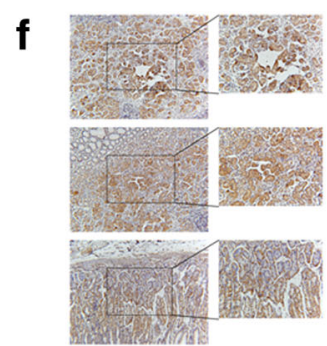

Adjacent tissues

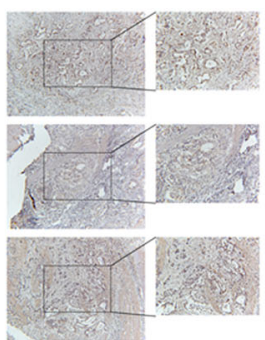

Gastric cancer tissues

Fig. 2 The proteomic analysis of TRIM3 expression in exosomes. a, LC-MS/MS analyses of the protein profiles of exosomes from the serum of gastric cancer patients and healthy controls. b. ELISA and western blot analyses of the expression of TRIM3 protein in exosomes from the serum of gastric cancer patients and healthy controls, ${ }^{* * *} P<0.001$. c, The expression of TRIM3 gene in gastric epithelial cells and gastric cancer cells was examined by using qRT-PCR and western blot. ${ }^{* *} P<0.01$. $\mathbf{d}$, The expression of TRIM3 gene in exosomes from the culture supernatants of gastric epithelial cells and gastric cancer cells was detected by using $q R T-P C R$ and western blot. ${ }^{*} P<0.05$, ${ }^{*} P<0.01$. e, The expression of TRIM3 gene in gastric cancer tissues and adjacent control tissues was detected by using qRT-PCR. ${ }^{* * *} P<0.001$. f, The expression of TRIM3 protein in gastric cancer tissues and adjacent control tissues was detected by using immunohistochemistry

and SGC-7901 cells (Fig. 3e, f). Overexpression of TRIM3 could markedly upregulate E-cadherin $(P<0.05$, $P<0.01)$ expression and downregulate $\mathrm{N}$-cadherin $(P<$ $0.01, P<0.05)$ and vimentin $(P<0.05, P<0.05)$ expression (Fig. 3g, h). Taken together, these results suggest that TRIM3 overexpression inhibits the proliferation and migration of MGC-803 and SGC-7901 cells in vitro.
TRIM3 knockdown promotes the proliferation and migration of gastric cancer cells in vitro

We knocked down TRIM3 expression by using siRNA in MGC-803 and SGC-7901 cells (Additional file 5: Figure S2c, d). TRIM3 knockdown cells showed significant increase in colony formation ability compared to scramble control knockdown cells (Fig. 4a, b). The 


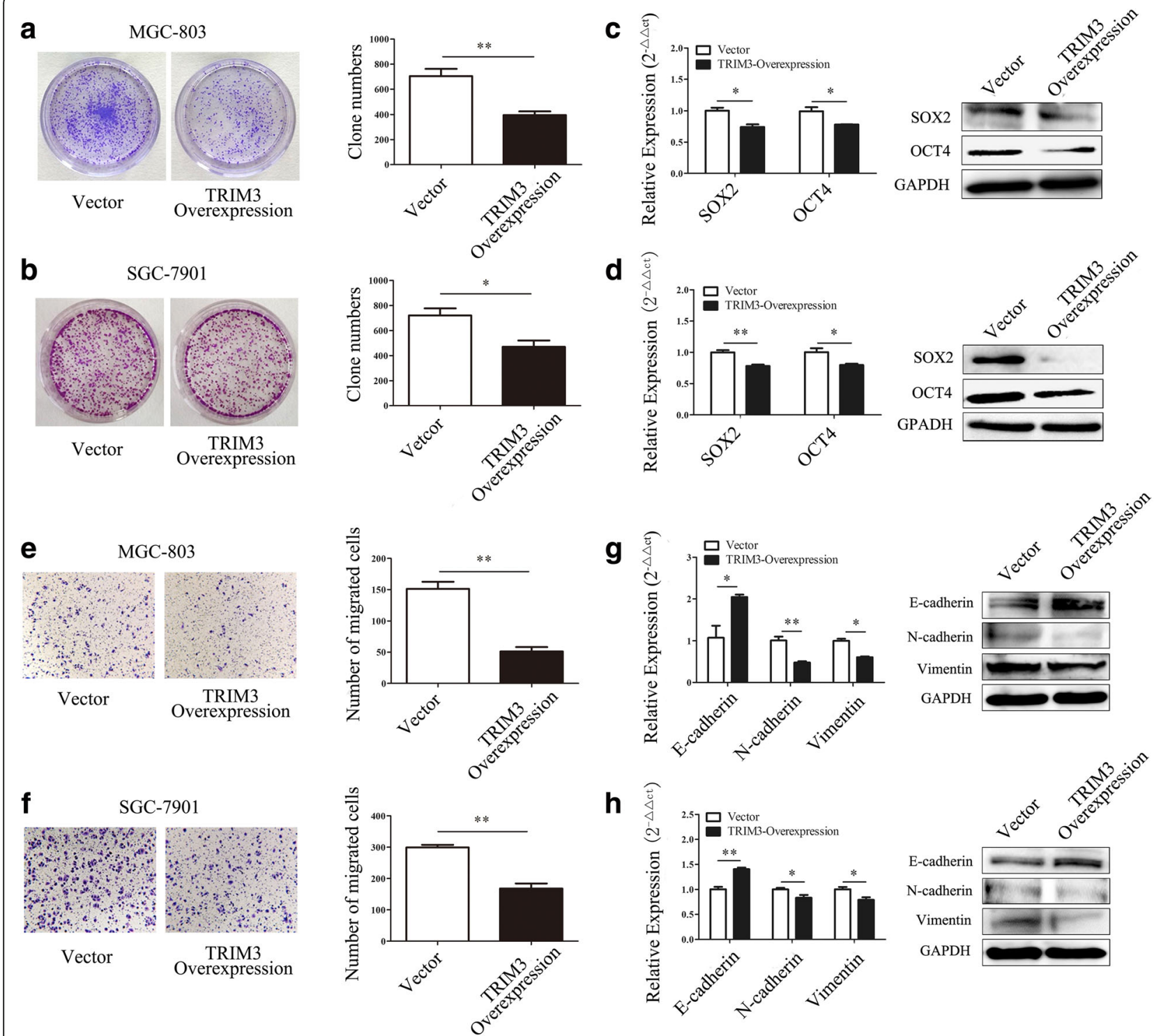

Fig. 3 TRIM3 overexpression inhibits gastric cancer cell proliferation and migration in vitro. $\mathbf{a}$ and $\mathbf{b}$, TRIM3 overexpression inhibits the colony formation abilities of MGC-803 (a) and SGC-7901 (b) cells. ${ }^{*} P<0.05,{ }^{* *} P<0.01$. $\mathbf{c}$ and $\mathbf{d}$, The expression of SOX2 and OCT4 in gastric cancer cells transfected with TRIM3, c, MGC-803; d, SGC-7901. ${ }^{*} P<0.05$, ${ }^{* *} P<0.01$. e and $\mathbf{f}$, TRIM3 overexpression inhibits the migration of MGC-803 (e) and SGC-7901 (f) cells. Magnification, 100x; ${ }^{* *} P<0.01$. g and $\mathbf{h}$, The expression of EMT associated genes in MGC-803 (g) and SGC-7901 (h) cells transfected with TRIM3. ${ }^{*} P<0.05,{ }^{* *} P<0.01$

knockdown of TRIM3 markedly upregulated SOX2 $(P$ $<0.01, P<0.01)$ and OCT4 $(P<0.01, P<0.01)$ expression in MGC-803 and SGC-7901 cells (Fig. 4c, d). The results of transwell migration assay showed that TRIM3 knockdown enhanced the migratory abilities of MGC-803 and SGC-7901 cells (Fig. 4e, f). The knockdown of TRIM3 markedly downregulated E-cadherin $(P<0.01, P<0.001)$ expression and upregulated N-cadherin $(P<0.05, P<0.01)$ and vimentin $(P$ $<0.01, P<0.01$ ) expression (Fig. $4 \mathrm{~g}, \mathrm{~h}$ ). Thus, these results suggest that TRIM3 promotes the proliferation and migration of MGC-803 and SGC-7901 in vitro.
TRIM3 overexpression suppresses gastric cancer growth and metastasis in vivo

To establish the role of TRIM3 as a tumor suppressor in vivo, we used the TRIM3 overexpressing MGC-803 cells to establish xenograft and peritoneal metastasis models in nude mice. In consistent with the in vitro results, the tumor weight and volume were decreased in the TRIM3 transfected MGC-803 group (Fig. 5a) $(P<0.01, P<0.05)$. We found that TRIM3 expression was up-regulated in TRIM3 transfected MGC-803 group by IHC Method (Fig. 5b). Compared with the vector group, the expression of PCNA was decreased in xenograft tumors in the 


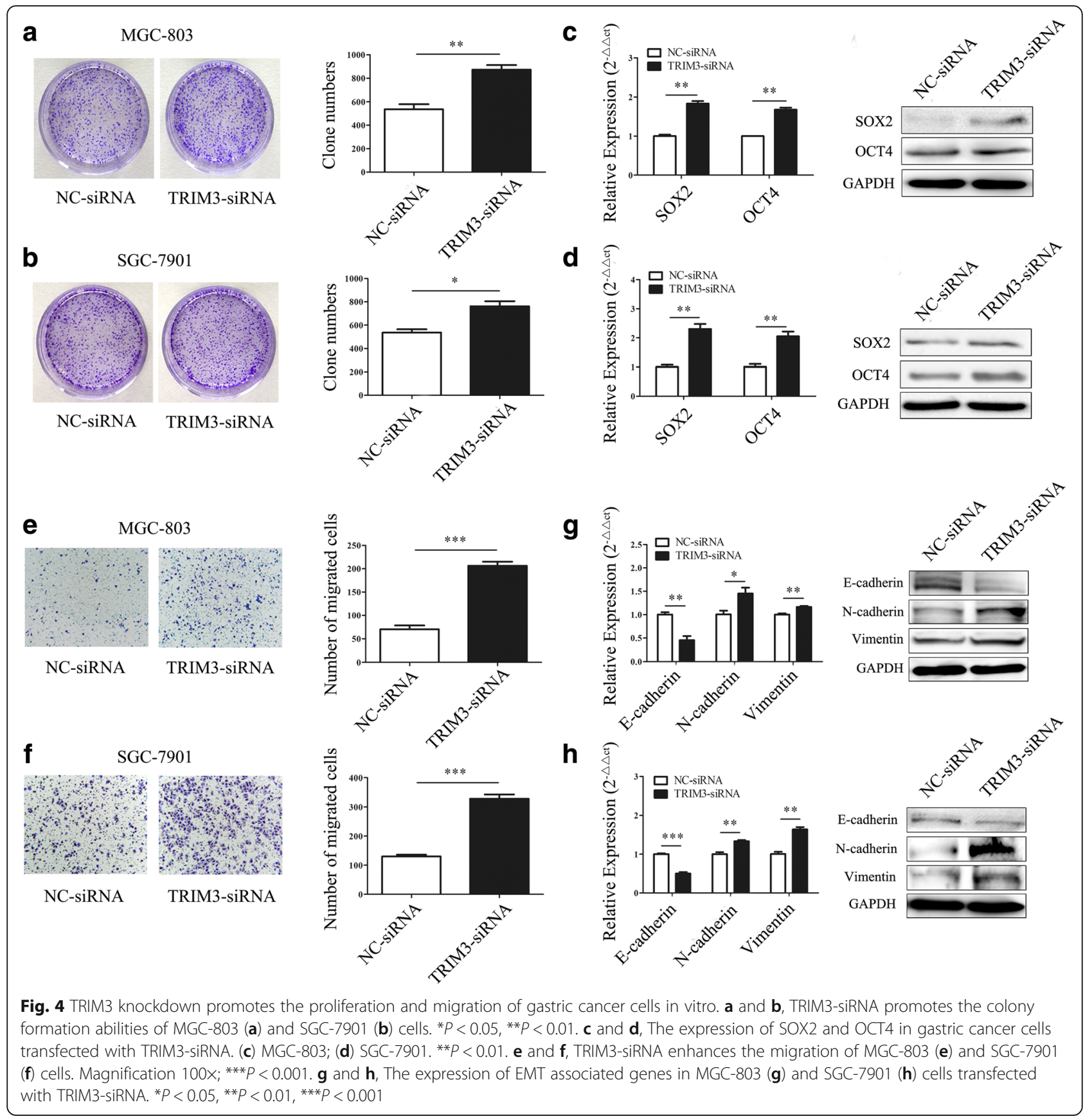

TRIM3 overexpression group (Fig. 5b). We next wanted to know whether TRIM3 overexpression also influenced the metastatic potential of gastric cancer cells in vivo. As shown in Fig. 5c, the number of metastatic tumor nodes in TRIM3 overexpression group was obviously less than that in the vector group $(P<0.01)$. The expression of TRIM3 was up-regulated in TRIM3 transfected MGC-803 group by IHC Method (Fig. 5d). The expression of E-cadherin was increased whereas that of $\mathrm{N}$-cadherin and Vimentin was decreased in the xenograft tumors in the TRIM3 overexpression group (Fig. 5d).
Altogether, these results suggest that TRIM3 plays a suppressive role in gastric cancer growth.

\section{TRIM3 knockdown promotes gastric cancer growth and metastasis in vivo}

To investigate whether TRIM3 downregulation could promote gastric cancer growth and metastasis in vivo, we used the MGC-803 cells transfected with TRIM3 siRNA to establish subcutaneous tumor xenograft and peritoneal metastasis models in nude mice. As shown in Fig. $5 \mathrm{e}$, the tumor weight and volume were increased in 
a

C

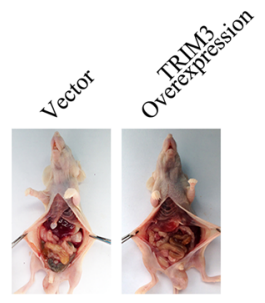

b
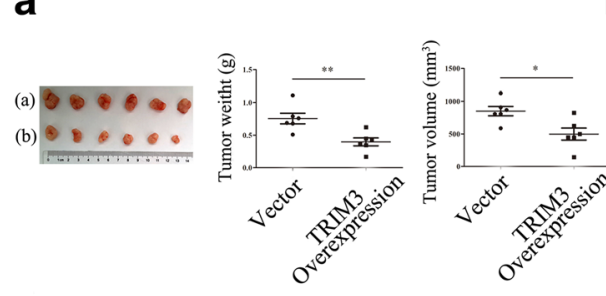

d

$\sum^{0}$

Vector

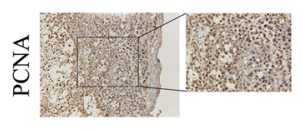

d

dector

TRIM3

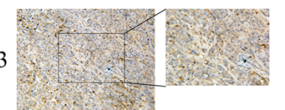

TRIM3-Overexpression
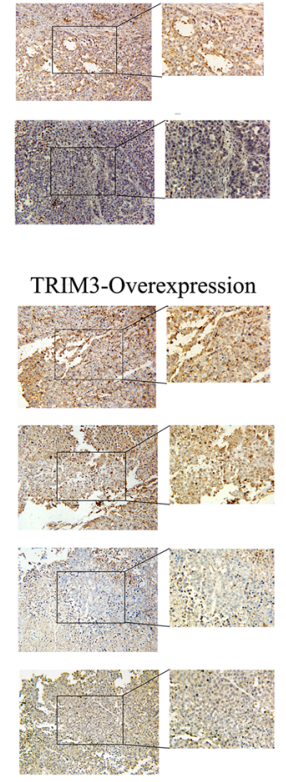

TRIM3-Overexpression

e

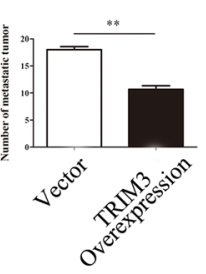

E-cadherin

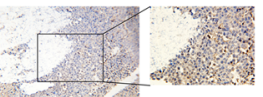

N-cadherin

in

Vimentin

in

f

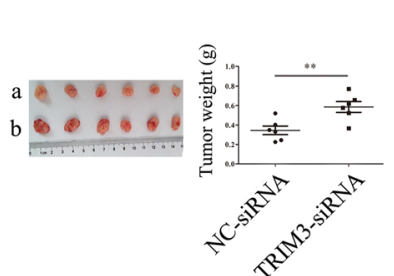

g

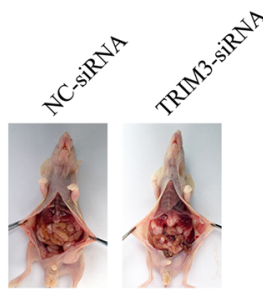<smiles>C1CC2CC1CC1CC2C1</smiles>

h

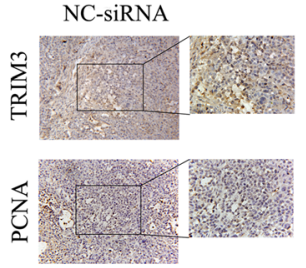

h

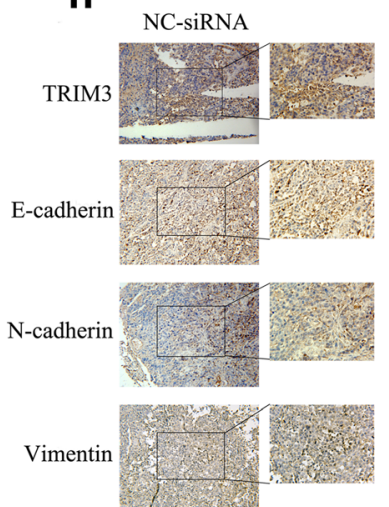

TRIM3-siRNA

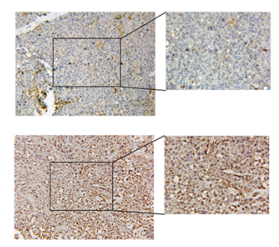

TRIM3-siRNA

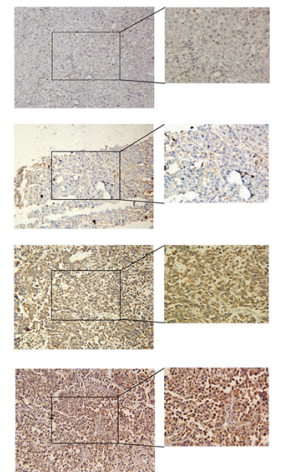

Fig. 5 TRIM3 overexpression inhibits gastric cancer growth and metastasis in vivo. a, The weight and volumes of tumors in control and TRIM3 overexpression groups. ((a). TRIM3-Vector; (b), TRIM3 overexpression). ${ }^{*} P<0.05,{ }^{*} P<0.01$. $\mathbf{b}$, The expression of TRIM3 and PCNA in subcutaneous tumor tissues was examined by using immunohistochemistry. Magnification, 200x (left panel); 400x (right panel). c, The number of metastatic tumor nodes in control and TRIM3 overexpression groups. ${ }^{*} P<0.01$. d , The expression of TRIM3 and EMT associated proteins in the metastatic tumor nodes was detected by using immunohistochemistry. Magnification, 200x (left panel); 400x (right panel). e, The weight and volume of tumors in control and TRIM3-siRNA groups. ${ }^{*} P<0.01$; ${ }^{*} P<0.05$. $\mathbf{f}$, The expression of TRIM3 and PCNA in subcutaneous tumor tissues was detected by using immunohistochemistry. Magnification, 200x (left panel); 400x (right panel). $\mathbf{g}$, The number of metastatic tumor nodes in control and TRIM3-siRNA groups. ${ }^{*} P<0.05$. $\mathbf{h}$, The expression of TRIM3 and EMT associated proteins in the metastatic tumor nodes was detected by using immunohistochemistry. Magnification, $200 \times$ (left panel); 400× (right panel) 
the TRIM3 siRNA transfected MGC-803 group $(P<$ $0.01, P<0.05)$. We found that TRIM3 expression was down-regulated in TRIM3 knockdown MGC-803 group by IHC Method (Fig. 5f). Compared with the scramble control group, the expression of PCNA was increased in xenograft tumors in the TRIM3 knockdown group (Fig. 5f). We next wanted to know whether TRIM3 downregulation also influenced the metastatic potential of gastric cancer cells in vivo. Representative images of peritoneal metastasis mice were shown in Fig. 5g. The number of metastatic tumor nodes in TRIM3 siRNA group was obviously more than that in the vector group $(P<0.05)$. The expression of TRIM3 was down-regulated in TRIM3 knockdown MGC-803 group by IHC Method (Fig. 5h). The expression of E-cadherin was decreased, whereas that of $\mathrm{N}$-cadherin and Vimentin was increased in the xenograft tumors in the TRIM3 siRNA group compared to the vector group (Fig. 5h). Taken together, these results suggest that TRIM3 downregulation enhances gastric cancer growth and metastasis in vivo.

\section{Exosomal TRIM3 inhibits the proliferation and migration of gastric cancer cells in vitro}

To demonstrate that the decreased expression of exosomal TRIM3 is involved in gastric cancer progression, we overexpressed TRIM3 in gastric cancer cells and extracted the TRIM3-overexprressing exosomes from the transfected cells. The expression of TRIM3 was upregulated in exosomes from TRIM3-overexpressing gastric cancer cells $(P<0.001)$ as detected by qRT-PCR and western bolt (Additional file 6: Figure S3). The results of confocal microscope and multispectral imaging flow cytometry showed that the gastric cancer cells efficiently uptook the exosomes that had been labeled with the fluorescent dye DiI (Additional file 7: Figure S4). MGC-803 and SGC-7901 cells were treated with different concentration of TRIM3-overexpressing exosomes $(10,25,50 \mu \mathrm{g})$ for $48 \mathrm{~h}$. The results of western blot assay showed that TRIM3 expression was increased in the gastric cancer cells incubated with the TRIM3-overexpressing exosomes (Additional file 8: Figure S5). We next tested the effects of TRIM3-overexpressing exosomes on gastric cancer cells. The treatment with $50 \mu \mathrm{g}$ TRIM3-overexpressing exosomes led to a significant decrease in the proliferation and migration of MGC-803 and SGC-7901 cells (Fig. 6a, b and e, f). However, no significant change was observed in gastric cancer cells treated with $10 \mu \mathrm{g}$ and $25 \mu \mathrm{g}$ exosomes (Additional file 9: Figure S6). Thus, we chose $50 \mu \mathrm{g}$ exosome for the following studies. The expression of SOX2 $(P<0.05, P<0.05)$ and OCT4 $(P<0.05$, $P<0.05)$ in gastric cancer cells treated with $50 \mu \mathrm{g}$ exosomes were significantly decreased compared to the control group (Fig. 6c, d). We also found that $\mathrm{N}$-cadherin
$(P<0.05, P<0.001)$ and vimentin $(P<0.05, P<0.001)$ were downregulated while E-cadherin $(P<0.05, P<0.05)$ was upregulated in $50 \mu \mathrm{g}$ exosome treated MGC-803 and SGC-7901 cells (Fig. 6g, h). These results suggest that the treatment with $50 \mu \mathrm{\mu g}$ TRIM3-overexpressing exosomes inhibit the proliferation and migration of gastric cancer cells.

\section{Exosomal TRIM3 inhibits gastric cancer growth and metastasis in vivo}

To determine the effects of TRIM3-overexpressing exosomes on the tumorigenicity and metastasis of gastric cancer, we conducted xenograft tumor and peritoneal metastasis models in nude mice. MGC-803 cells pre-treated with $50 \mu \mathrm{g}$ TRIM3-overexpression exosomes for $48 \mathrm{~h}$ were subcutaneously implanted or intraperitoneal implanted into nude mice. The tumor weight $(P<0.05)$ and volume $(P<0.05)$ in mice injected with MGC-803 cells pre-treated with $50 \mu \mathrm{g}$ TRIM3-overexpressing exosomes were significantly lower than that in controls (Fig. 7a). We found that TRIM3 expression was up-regulated in xenograft tumors in the TRIM3-overexpressing exosomes treated group by IHC Method (Fig. $7 \mathrm{~b})$. Compared with the vector group, the expression of PCNA was decreased in xenograft tumors in the TRIM3-overexpressing exosomes treated group (Fig. 7b). As shown in Fig. 7c, the number of metastatic tumor nodes in $50 \mu \mathrm{g}$ TRIM3-overexpressing exosomes treated group was obviously less than in the vector group $(P<$ $0.05)$. The expression of TRIM3 was up-regulated in xenograft tumors in the TRIM3-overexpressing exosomes treated group (Fig. 7d). We then find, the expression of E-cadherin was increased whereas that of $\mathrm{N}$-cadherin and Vimentin was decreased in xenograft tumors in the TRIM3-overexpressing exosomes treated group (Fig. 7d). Altogether, these results suggest that TRIM3overexpressing exosomes could transfer TRIM3 to gastric cancer cells, which inhibit gastric cancer growth and metastasis in vivo.

\section{TRIM3 downregulation is associated with miR-20a in gastric cancer}

To investigate the possible upstream regulator of TRIM3, we used Targetscan to predict TRIM3-targeting miRNAs and found that miR-20a potentially bound to TRIM3 mRNA. To confirm this, we constructed the TRIM3 3'UTR containing the target sequences, or the mutants, into a dual-luciferase reporter vector (Fig. 8a, b). The transfection of miR-20a suppressed the luciferase activity of the wild type TRIM3 3'UTR (WT) $(P<0.01)$, while mutation of the miR-20a binding sites (Mut) reversed this suppression. On the contrary, miR-20a-inhibitor enhanced the luciferase activity of the wild type TRIM3 3'UTR $(P<0.01)$, while mutation of the miR-20a 


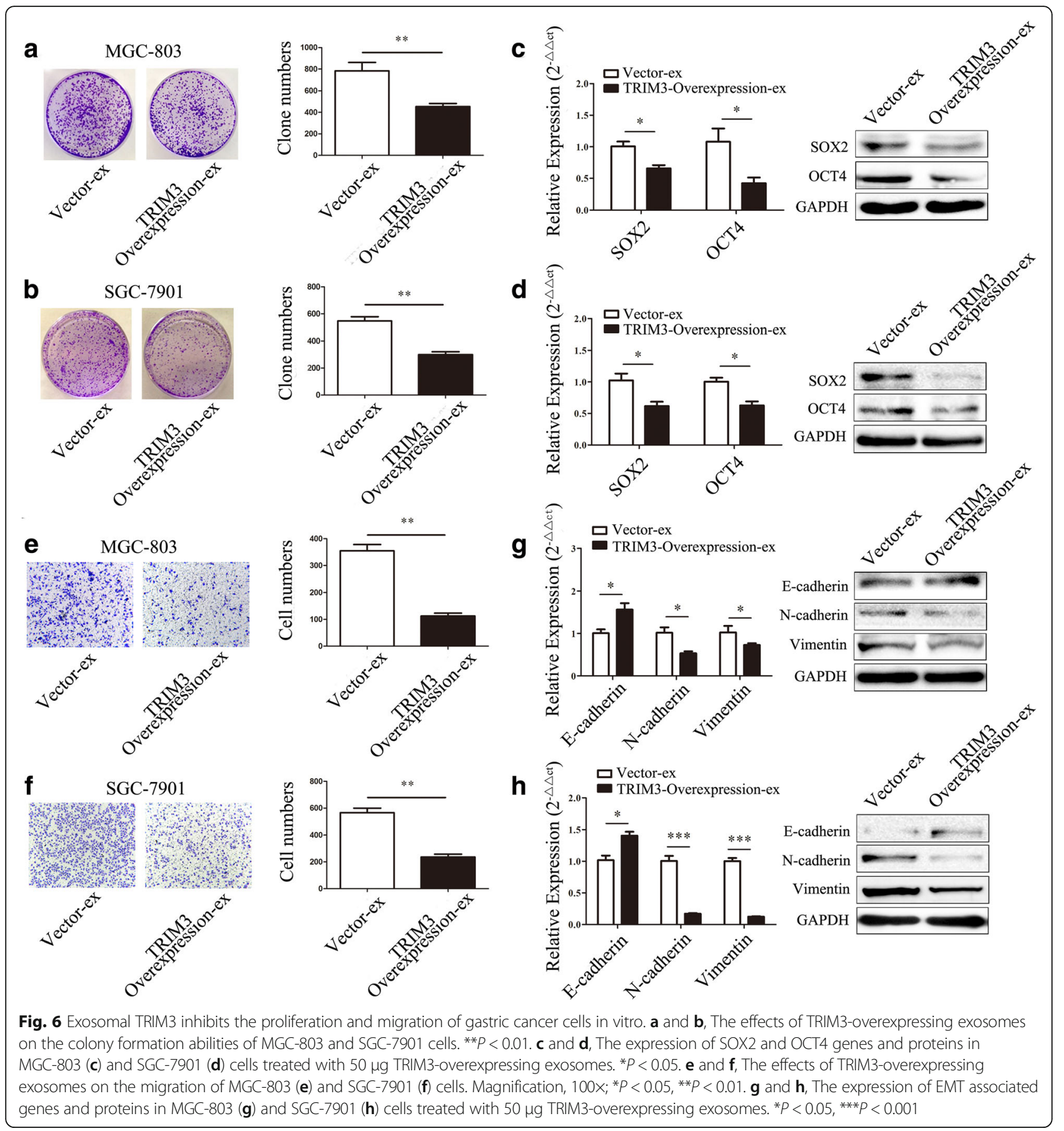

binding sites blocked this enhancement. In addition, the expression of miR-20a was significantly upregulated in gastric cancer tissues compared to the matched control tissues $(P<0.01) \quad$ (Fig. 8c). The level of TRIM3 was negatively correlated with that of miR-20a in gastric cancer tissues. To further confirm the direct effect of miR-20a on TRIM3, we transfect miR-20a-mimics and miR-20a-inhibitor into gastric cancer cell lines. The results of qRT-PCR confirmed the decrease of TRIM3 expression after miR-20a-mimics transfection in MGC-803 $(P<0.05)$ and SGC-7901 $(P<0.05)$, and the protein expression level of TRIM3 were significantly lower than that of control group by western blot (Fig. $8 \mathrm{~d}$ and e). We also found that TRIM3 were upregulated after miR-20a-inhibitor transfection in MGC-803 $(P<0.01)$ and SGC-7901 $(P<0.001)$, the results of western blot showed that miR-20a-inhibitor transfection enhanced the expression of TRIM3 in MGC-803 and SGC-7901 cells (Fig. 8f and g). Thus, these 


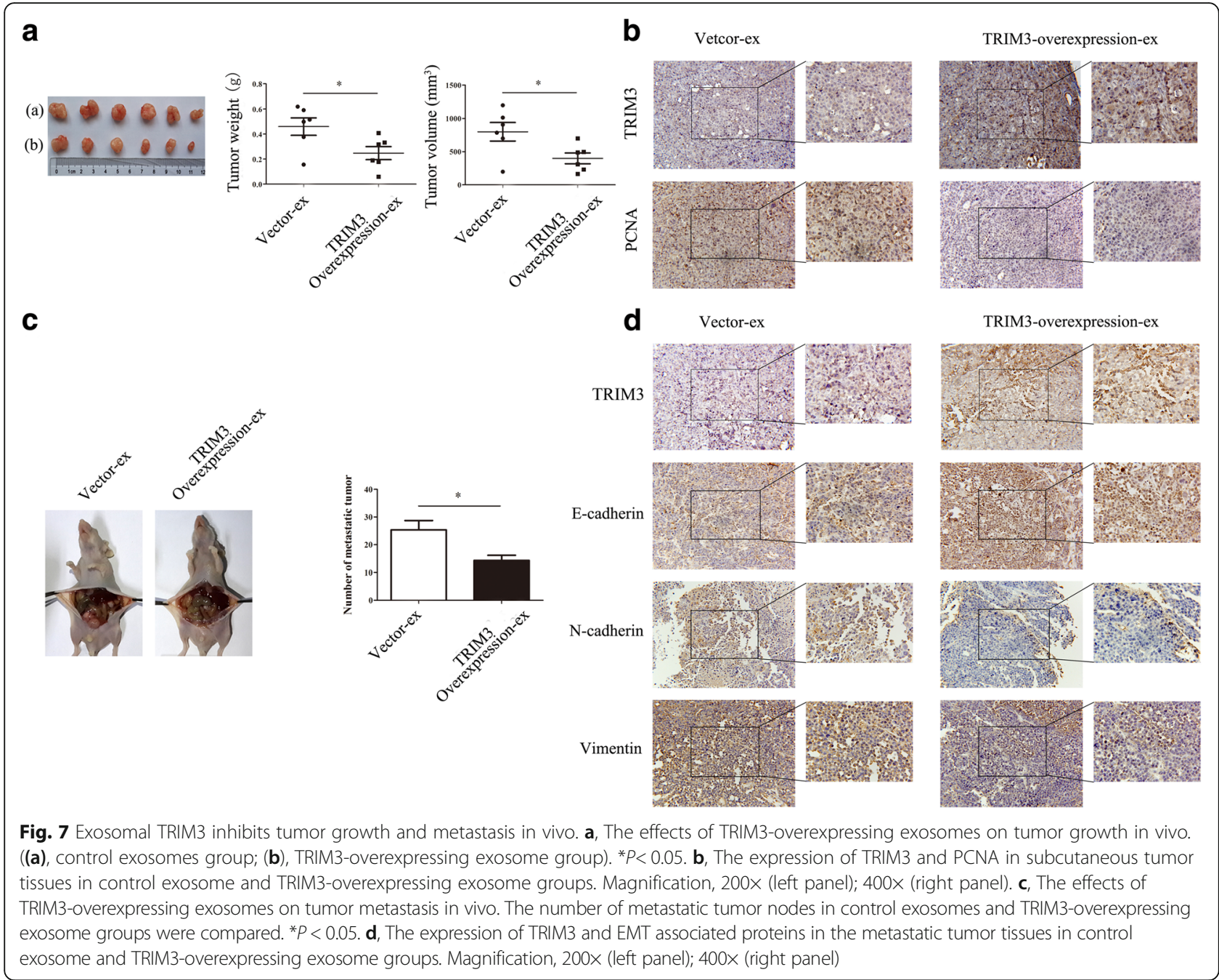

results suggest that TRIM3 is the direct target of miR-20a, TRIM3 was negatively associated with miRNA-20a, and directly regulated by miR-20a.

\section{Discussion}

Cancer cells release excessive quantities of exosomes. The plasma of patients with acute myeloid leukemia (AML) were found to contain a 60 -fold greater quantity of exosomes than that of normal donors [19]. Melanoma cells also release large quantities of exosomes, in contrast to normal melanocytes $[20,21]$. Patients with ovarian cancer exhibit significantly increased levels of serum exosomes compared to benign disease or healthy controls [22]. Silva et al. have reported that high levels of exosomes in the plasma of colorectal cancer patients were significantly associated with poorly differentiated tumors and with decreased overall survival [23]. These reports indicate that the level of exosomes is elevated in the circulation of cancer patients and is positively associated with disease progression. In this study, we found that the concentration of exosomes from the serum of gastric cancer patients was higher than that from the healthy controls, which is consistent with that reported in the other cancers, suggesting that the increased level of exosomes is an important indicator of cancer progression.

Exosomes perform a variety of extracellular functions in the processes of cancer development and progression $[24,25]$. Exosomes contain a wide range of functional proteins and nucleic acids that can be transferred to local and distant recipient cells [26-29]. Tumor cells secrete large amounts of exosomes that promote tumor progression through communication between the tumor and surrounding stromal tissue, activation of proliferative and angiogenic pathways, and initiation of premetastatic sites [30-34]. Therefore, exosomes are an important component of the tumor microenvironment and are currently considered to be one of the main 


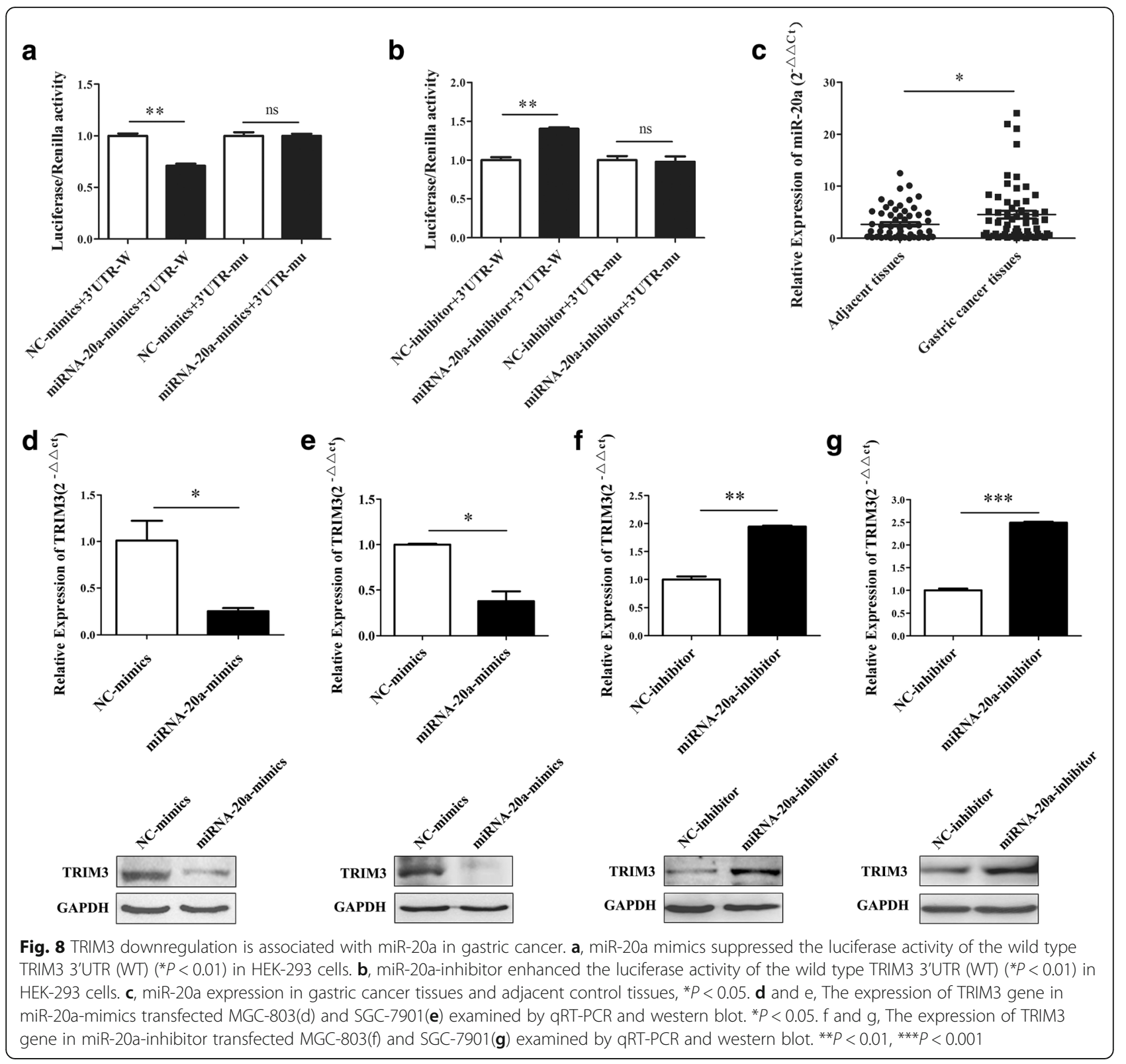

contributors to tumor progression and metastasis [24]. In this study, we initially purified exosomes from the serum of gastric cancer patients and explored the protein profiles of exosomes by using LC-MS/MS. We identified a total of 243 differentially expressed proteins between the exosomes from the serum of gastric cancer patients and that from the serum of healthy controls. The altered expression of proteins in exosomes may act as messengers that transport signals between cells to promote cancer progression.

At present, there are few studies about the role of TRIM3 in cancer. It has been reported that the mRNA and protein levels of TRIM3 are downregulated in hepatocellular carcinoma (HCC) and are correlated with an unfavorable prognosis in patients with HCC, suggesting that TRIM3 could be a prognostic marker and novel therapeutic target for HCC [35]. Liu et al. have reported that TRIM3 is a tumor suppressor mapping to chromosome 11p15.5 and that it might block tumor growth by sequestering p21 and preventing it from facilitating the accumulation of cyclin D1-cdk4 [17]. Chen et al. have shown that TRIM3 acts as a tumor suppressor in GBM by restoring asymmetric cell division [16]. Boulay et al. have reported the homozygous deletions of TRIM3 in brain tumor [36]. Piao et al. suggest that TRIM3 functions as a tumor suppressor in colorectal cancer 
(CRC), which is exerted partially through the regulation of p53 [37]. We found that TRIM3 was significantly downregulated in gastric cancer tissues. We investigated the functional roles of TRIM3 in gastric cancer by using gain- and loss-of-function studies. We found that TRIM3 inhibited gastric cancer growth and metastasis through the regulation of stem cell factors and EMT regulators, indicating that TRIM3 also plays tumor suppressive roles in gastric cancer. However, more studies are warranted to clarify the molecular mechanism responsible for the roles of TRIM3 in gastric cancer. We further identified TRIM3 as a direct target of miR-20a, and negatively regulated by miR-20a. MiR-20a act as an oncogenic miRNA that has been previously reported to be overexpressed in most cancers, suggesting that the upregulated expression of miRNAs in cancer may be associated with the decreased expression of TRIM in gastric cancer.

Exosomes contain bioactive molecules that reflect the pathological state of the originated cells, thus providing an enriched source of biomarkers [38-40]. Melo et al. have reported that the cell surface proteoglycan glypican-1 can be detected on exosomes harvested from the serum of patients with pancreatic cancer and breast cancer [41]. EBV-positive nasopharyngeal carcinoma (NPC) cell-derived exosomes contain HIF- $1 \alpha$, which increases the migration and invasiveness of EBV-negative NPC cells [42]. In this study, we demonstrated that the expression of TRIM3 was lowly expressed in exosomes from the serum of gastric cancer patients and from the culture supernatants of gastric cancer cells, suggesting that the decreased expression of TRIM3 in serum exosomes could be a diagnostic biomarker for gastric cancer.

The tumor suppressive role of TRIM3 in gastric cancer and the presence of TRIM3 in exosomes led us to explore the possibility of delivering TRIM3 by exosomes to treat gastric cancer. We overexpressed TRIM3 in gastric cancer cells and collected the TRIM3-overexpressing exosomes and incubated gastric cancer cells with the TRIM3-overexpressing exosomes. We found that the TRIM3-overexpressing exosomes could be internalized into the gastric cancer cells. Exosomal TRIM3 could inhibit gastric cancer growth and metastasis in vitro and in vivo, suggesting that exosomes-mediated transfer of TRIM3 might serve as a new strategy for gastric cancer therapy.

\section{Conclusions}

Our findings suggest that TRIM3 expression is downregulated in gastric cancer. TRIM3 functions as a tumor suppressor by inhibiting gastric cancer growth and metastasis. TRIM3 could be a utilized as a diagnostic biomarker and therapeutic target for gastric cancer.

\section{Additional files}

Additional file 1: Table S1. Sequences of TRIM3-siRNA. (DOCX 18 kb)

Additional file 2: Table S2. Primer sequences and amplified fragment products. (DOCX $19 \mathrm{~kb}$ )

Additional file 3: Table S3. Sequences of miR-20a mimics and inhibitor. (DOCX $18 \mathrm{~kb}$ )

Additional file 4: Figure S1. Analysis of the proteins in exosome derived from serum of gastric cancer patients and healthy control. (JPG $454 \mathrm{~kb}$ )

Additional file 5: Figure S2. Validation of TRIM3 expression levels in TRIM3 overexpression and knockdown cells. $a$ and $b$, The expression of TRIM3 in MGC-803 and SGC-7901 cells transfected with TRIM3 was detected by using qRT-PCR and western blot. ${ }^{* *} P<0.001$. $c$ and $d$, The expression of TRIM3 in MGC-803 and SGC-7901 transfected with TRIM3siRNA was determined by using qRT-PCR and western blot. ${ }^{* * *} P<0.001$ (JPG 607 kb)

Additional file 6: Figure S3. The expression of TRIM3 in exosomes from gastric cancer cells transfected with TRIM3. a, MGC-803; b, SGC-7901; ***P $<0.001$. (JPG $259 \mathrm{~kb}$ )

Additional file 7: Figure S4. Gastric cancer cells internalize exosomes. a Exosome internalization into gastric cancer cells was determined by using confocal microscopy. Magnification, 200x ((a) and (b)); 400× ((c) and $(d))$. b, Exosome internalization into gastric cancer cells was determined by using imaging flow cytometry. (JPG 3089 kb)

Additional file 8: Figure S5. The expression of TRIM3 in gastric cancer cells treated with control exosomes and TRIM3-overexpressing exosomes. (JPG $130 \mathrm{~kb}$ )

Additional file 9: Figure S6. The effects of TRIM3-overexpressing exosomes on the proliferation and migration of gastric cancer cells in vitro. $a$ and $b$, The effects of TRIM3-overexpressing exosomes on the colony formation abilities of MGC-803 (a) and SGC-7901 (b) cells. ${ }^{*} P<0.01$. $c$ and $d$, The effects of TRIM3-overexpressing exosomes on the migration of MGC-803 (c) and SGC-7901 (d) cells. ${ }^{*} P<0.05$, **P $<0.01$. (JPG $5700 \mathrm{~kb}$ )

\section{Abbreviations}

ELISA: Enzyme-linked immunosorbent assay; EMT: Epithelial-mesenchymal transition; ex: Exosome; GC: Gastric cancer; IHC: Immunohistochemistry; miR20a: miRNA-20a.; MVBs: Multivesicular bodies; TRIM: Tripartite motif; TRIM3: Tripartite motif-containing 3

\section{Acknowledgments}

The funding body had no role in study design, data collection and analysis, decision to publish, or preparation of the manuscript.

\section{Funding}

This work was supported by the National Natural Science Foundation of China (81572075, 81702080, 81672416, 81702078), the Natural Science Foundation of the Jiangsu Province (BK20141303, BK20170356), Jiangsu Province for Outstanding Sci-tech Innovation Team in Colleges and Universities (SJK2013-10), Jiangsu Province's Outstanding Medical Academic Leader and Sci-tech Innovation Team Program (LJ201117), Jiangsu Key Laboratory of Medical Science and Laboratory Medicine (JSKLM-2014-004), Jiangsu Province's Major Project in Research and Development (BE2015667, BE2016717), the Priority Academic Program Development of Jiangsu Higher Education Institutions, Special funded projects of national postdoctoral fund (2017 T100337), Postdoctoral Science Foundation of China (2016 M591791). Natural science fund for colleges and universities of Jiangsu Province (17KJB320016), Suzhou Science and Technology Project (SYS201728).

\section{Availability of data and materials}

The datasets supporting the conclusions of this article are included within the article and additional files.

\section{Authors' contributions}

$\mathrm{HF}$ and $\mathrm{HY}$ performed and analyzed the experiments and wrote the manuscript. $X Z, B W$ and $M W$ analyzed the experiments and critically revised 
the manuscript. JM and $\mathrm{XL}$ helped to perform the experiments. BZ and ZS helped to correct the manuscript. WX and HQ designed and supervised the study. All authors have read and approved the final manuscript.

\section{Ethics approval and consent to participate}

This study was approved by the ethics committee of Jiangsu University (2012258), and written informed consent was obtained from all patients.

\section{Consent for publication}

Not applicable.

\section{Competing interests}

The authors declare that they have no competing interests.

\section{Publisher's Note}

Springer Nature remains neutral with regard to jurisdictional claims in published maps and institutional affiliations.

\begin{abstract}
Author details
${ }^{1}$ Jiangsu Key Laboratory of Medical Science and Laboratory Medicine, School of Medicine, Jiangsu University, 301 Xuefu Road, Zhenjiang 212013, Jiangsu, China. ${ }^{2}$ Center for Clinical Laboratory, the First Affiliated Hospital of Soochow University, 188 Shizi Street, Suzhou 215006, Jiangsu, China. ${ }^{3}$ Department of Clinical Laboratory, The Second Affiliated Hospital of Soochow University, 1055 Sanxiang Road, Suzhou 215004, Jiangsu, China. ${ }^{4}$ Department of Oncology, The Second Affiliated Hospital of Soochow University, 1055 Sanxiang Road, Suzhou 215004, Jiangsu, China.
\end{abstract}

Received: 16 November 2017 Accepted: 4 July 2018

Published online: 21 July 2018

\section{References}

1. Jemal A, Siegel R, Ward E, Murray T, Xu J, Smigal C, Thun MJ. Cancer statistics, 2006. CA Cancer J Clin. 2006;56(2):106-30.

2. Saka M, Morita S, Fukagawa T, Katai H. Present and future status of gastric cancer surgery. Jpn J Clin Oncol. 2011;41(3):307-13.

3. Boukouris $\mathrm{S}$, Mathivanan S. Exosomes in bodily fluids are a highly stable resource of disease biomarkers. Proteomics Clin Appl. 2015;9(3-4):358-67.

4. Thery C, Ostrowski M, Segura E. Membrane vesicles as conveyors of immune responses. Nat Rev Immunol. 2009;9(8):581-93.

5. Kowal J, Tkach M, Thery C. Biogenesis and secretion of exosomes. Curr Opin Cell Biol. 2014;29:116-25.

6. Vlassov AV, Magdaleno S, Setterquist R, Conrad R. Exosomes: current knowledge of their composition, biological functions, and diagnostic and therapeutic potentials. Biochim Biophys Acta. 2012;1820(7):940-8.

7. Duijvesz D, Luider T, Bangma $\mathrm{CH}$, Jenster $\mathrm{G}$. Exosomes as biomarker treasure chests for prostate cancer. Eur Urol. 2011;59(5):823-31.

8. Hessvik NP, Sandvig K, Llorente A. Exosomal miRNAs as biomarkers for prostate cancer. Front Genet. 2013:4:36.

9. Rabinowits G, Gercel-Taylor C, Day JM, Taylor DD, Kloecker GH. Exosomal microRNA: a diagnostic marker for lung cancer. Clin Lung Cancer. 2009; 10(1):42-6.

10. Bard MP, Hegmans JP, Hemmes A, Luider TM, Willemsen R, Severijnen LA, van Meerbeeck JP, Burgers SA, Hoogsteden HC, Lambrecht BN. Proteomic analysis of exosomes isolated from human malignant pleural effusions. Am J Respir Cell Mol Biol. 2004;31(1):114-21.

11. Street JM, Barran PE, Mackay CL, Weidt S, Balmforth C, Walsh TS, Chalmers RT, Webb DJ, Dear JW. Identification and proteomic profiling of exosomes in human cerebrospinal fluid. J Transl Med. 2012;10:5.

12. Hatakeyama S. TRIM proteins and cancer. Nat Rev Cancer. 2011;11(11):792-804.

13. Cambiaghi V, Giuliani V, Lombardi S, Marinelli C, Toffalorio F, Pelicci PG. TRIM proteins in cancer. Adv Exp Med Biol. 2012;770:77-91.

14. El-Husseini AE, Vincent SR. Cloning and characterization of a novel RING finger protein that interacts with class V myosins. J Biol Chem. 1999;274(28): 19771-7.

15. El-Husseini AE, Kwasnicka D, Yamada T, Hirohashi S, Vincent SR. BERP, a novel ring finger protein, binds to alpha-actinin-4. Biochem Biophys Res Commun. 2000;267(3):906-11.

16. Chen G, Kong J, Tucker-Burden C, Anand M, Rong Y, Rahman F, Moreno CS, Van Meir EG, Hadjipanayis CG, Brat DJ. Human brat ortholog TRIM3 is a tumor suppressor that regulates asymmetric cell division in glioblastoma. Cancer Res. 2014;74(16):4536-48.

17. Liu Y, Raheja R, Yeh N, Ciznadija D, Pedraza AM, Ozawa T, Hukkelhoven E, Erdjument-Bromage $\mathrm{H}$, Tempst $\mathrm{P}$, Gauthier NP, et al. TRIM3, a tumor suppressor linked to regulation of p21(Waf1/Cip1). Oncogene. 2014;33(3):308-15.

18. Raheja R, Liu Y, Hukkelhoven E, Yeh N, Koff A. The ability of TRIM3 to induce growth arrest depends on RING-dependent E3 ligase activity. Biochem J. 2014;458(3):537-45.

19. Szczepanski MJ, Szajnik M, Welsh A, Whiteside TL, Boyiadzis M. Blast-derived microvesicles in sera from patients with acute myeloid leukemia suppress natural killer cell function via membrane-associated transforming growth factor-beta1. Haematologica. 2011;96(9):1302-9.

20. Felicetti F, Parolini I, Bottero L, Fecchi K, Errico MC, Raggi C, Biffoni M Spadaro F, Lisanti MP, Sargiacomo M, Care A. Caveolin-1 tumor-promoting role in human melanoma. Int J Cancer. 2009:125(7):1514-22.

21. Xiao D, Ohlendorf J, Chen Y, Taylor DD, Rai SN, Waigel S, Zacharias W, Hao $\mathrm{H}$, McMasters KM. Identifying mRNA, microRNA and protein profiles of melanoma exosomes. PLoS One. 2012;7(10):e46874.

22. Taylor DD, Gercel-Taylor C. MicroRNA signatures of tumor-derived exosomes as diagnostic biomarkers of ovarian cancer. Gynecol Oncol. 2008;110(1):13-21.

23. Silva J, Garcia V, Rodriguez M, Compte M, Cisneros E, Veguillas P, Garcia JM, Dominguez G, Campos-Martin Y, Cuevas J, et al. Analysis of exosome release and its prognostic value in human colorectal cancer. Genes Chromosomes Cancer. 2012;51(4):409-18.

24. Peinado $H$, Lavotshkin $S$, Lyden D. The secreted factors responsible for premetastatic niche formation: old sayings and new thoughts. Semin Cancer Biol. 2011;21(2):139-46.

25. O'Loughlin AJ, Woffindale CA, Wood MJ. Exosomes and the emerging field of exosome-based gene therapy. Curr Gene Ther. 2012;12(4):262-74.

26. Mathivanan S, Ji H, Simpson RJ. Exosomes: extracellular organelles important in intercellular communication. J Proteome. 2010;73(10):1907-20.

27. Valadi H, Ekstrom K, Bossios A, Sjostrand M, Lee JJ, Lotvall JO. Exosomemediated transfer of mRNAs and microRNAs is a novel mechanism of genetic exchange between cells. Nat Cell Biol. 2007;9(6):654-9.

28. Skog J, Wurdinger T, van Rijn S, Meijer DH, Gainche L, Sena-Esteves M, Curry WJ, Carter BS, Krichevsky AM, Breakefield XO. Glioblastoma microvesicles transport RNA and proteins that promote tumour growth and provide diagnostic biomarkers. Nat Cell Biol. 2008;10(12):1470-6.

29. Martins VR, Dias MS, Hainaut P. Tumor-cell-derived microvesicles as carriers of molecular information in cancer. Curr Opin Oncol. 2013;25(1): $66-75$.

30. King HW, Michael MZ, Gleadle JM. Hypoxic enhancement of exosome release by breast cancer cells. BMC Cancer. 2012;12(1):421.

31. Webber J, Steadman R, Mason MD, Tabi Z, Clayton A. Cancer exosomes trigger fibroblast to myofibroblast differentiation. Cancer Res. 2010;70(23): 9621-30.

32. Liu C, Yu S, Zinn K, Wang J, Zhang L, Jia Y, Kappes JC, Barnes S, Kimberly RP, Grizzle WE, Zhang HG. Murine mammary carcinoma exosomes promote tumor growth by suppression of NK cell function. J Immunol. 2006;176(3): 1375-85.

33. Hood $J \mathrm{~L}$, San RS, Wickline SA. Exosomes released by melanoma cells prepare sentinel lymph nodes for tumor metastasis. Cancer Res. 2011;71(11): 3792-801.

34. Peinado H, Aleckovic M, Lavotshkin S, Matei I, Costa-Silva B, MorenoBueno G, Hergueta-Redondo M, Williams C, Garcia-Santos G, Ghajar C, et al. Melanoma exosomes educate bone marrow progenitor cells toward a pro-metastatic phenotype through MET. Nat Med. 2012;18(6): 883-91.

35. Chao J, Zhang XF, Pan QZ, Zhao JJ, Jiang SS, Wang Y, Zhang JH, Xia JC. Decreased expression of TRIM3 is associated with poor prognosis in patients with primary hepatocellular carcinoma. Med Oncol. 2014;31(8):102.

36. Boulay JL, Stiefel U, Taylor E, Dolder B, Merlo A, Hirth F. Loss of heterozygosity of TRIM3 in malignant gliomas. BMC Cancer. 2009;9(1):71.

37. Piao MY, Cao HL, He NN, Xu MQ, Dong WX, Wang WQ, Wang BM, Zhou B. Potential role of TRIM3 as a novel tumour suppressor in colorectal cancer (CRC) development. Scand J Gastroenterol. 2016;51(5):572-82.

38. Al-Nedawi K, Meehan B, Micallef J, Lhotak V, May L, Guha A, Rak J. Intercellular transfer of the oncogenic receptor EGFRvIII by microvesicles derived from tumour cells. Nat Cell Biol. 2008;10(5):619-24.

39. Demory BM, Higginbotham JN, Franklin JL, Ham AJ, Halvey PJ, Imasuen IE, Whitwell C, Li M, Liebler DC, Coffey RJ. Proteomic analysis of exosomes 
from mutant KRAS colon cancer cells identifies intercellular transfer of mutant KRAS. Mol Cell Proteomics. 2013;12(2):343-55.

40. Costa-Silva B, Aiello NM, Ocean AJ, Singh S, Zhang H, Thakur BK, Becker A, Hoshino A, Mark MT, Molina H, et al. Pancreatic cancer exosomes initiate pre-metastatic niche formation in the liver. Nat Cell Biol. 2015;17(6):816-26.

41. Melo SA, Luecke LB, Kahlert C, Fernandez AF, Gammon ST, Kaye J, LeBleu VS, Mittendorf EA, Weitz J, Rahbari N, et al. Glypican-1 identifies cancer exosomes and detects early pancreatic cancer. Nature. 2015;523:177-82.

42. Aga M, Bentz GL, Raffa S, Torrisi MR, Kondo S, Wakisaka N, Yoshizaki T, Pagano JS, Shackelford J. Exosomal HIF1alpha supports invasive potential of nasopharyngeal carcinoma-associated LMP1-positive exosomes. Oncogene. 2014;33(37):4613-22.

Ready to submit your research? Choose BMC and benefit from:

- fast, convenient online submission

- thorough peer review by experienced researchers in your field

- rapid publication on acceptance

- support for research data, including large and complex data types

- gold Open Access which fosters wider collaboration and increased citations

- maximum visibility for your research: over $100 \mathrm{M}$ website views per year 